\title{
Primary Synovial Sarcoma of Lung
}

\author{
Dr. J. Rajitha ${ }^{1}$, Dr. S.Srikanth ${ }^{2 *}$
}

${ }_{1}^{1}$ Associate Professor, Department of Pathology, Chalmeda Ananda Rao Institute of Medical Sciences, Karimnagar, Telangana India
${ }^{2}$ Professor, Department of Pathology, Malla Reddy Institute of Medical Sciences, Hyderababd India

DOI: $10.36347 /$ sjmcr.2020.v08i10.013

| Received: 30.09 .2020 | Accepted: 14.10.2020 | Published: 23.10.2020

*Corresponding author: Dr. S.Srikanth

Abstract

Primary synovial sarcoma of lung is an extremely rare tumor. We report a case of a 50 year old male, who complained shortness of breath and hemoptysis. He had heterogeneously enhancing soft tissue density in right upper lobe. Trucut biopsy revealed spindle cell neoplasm and he underwent right lobectomy. Histopathological examination of lobectomy specimen revealed monophasic variant of synovial sarcoma. On immunohistochemistry tumor cells positive for vimentin, bcl-2, CD99 and immunonegative for cytokeratin. Based on clinical, imageological, histopathology and immunohistochemistry finally concluded it as primary synovial sarcoma of lung.

Keywords: Primary synovial sarcoma, immunohistochemistry.

Copyright (C) 2020 The Author(s): This is an open-access article distributed under the terms of the Creative Commons Attribution 4.0 International License (CC BY-NC 4.0) which permits unrestricted use, distribution, and reproduction in any medium for non-commercial use provided the original author and source are credited.

\section{INTRODUCTION}

Most of the lung tumors are malignant in origin and carcinoma by nature. Primary synovial sarcoma of lung is an extremely rare tumor, accounting for less than $0.5 \%$ of all lung tumors[1]. The variety of soft tissue sarcomas reflects the range of the mesenchymal tissues present in the lung. Three most common sarcomas include leiomyosarcoma,malignant fibrous histiocytoma and synovial sarcoma.

Pulmonary SS usually presents in young to middle age adults and shows no gender predilection. Cough, often with haemoptysis is the most common clinical manifestation, followed by chest pain. Lowgrade fever and weight loss are rare. These tumours can also present as incidental tumours on chest X-ray.The diagnosis of primary pulmonary synovial sarcoma requires clinical, radiological, pathological and immunohistochemical investigations to exclude alternative primary tumors and metastatic sarcoma [2].

\section{Case Report}

A 50-yr-old male presented with cough with expectoration for 1 month, he had three episodes of hemoptysis in a one month period. He was also complaining of shortness of breath. He had past history of hemoptysis 3 months, subsided on treatment. He was chronic smoker and alcoholic.

On examination there were no pallor, lymphadenopathy and oedema. His pulse $-86 / \mathrm{min}$, blood pressure $-130 / 88 \mathrm{~mm} \mathrm{Hg}$ and respiratory rate- 24 breaths/min. Examination of respiratory system revealed decreased movement of the right side chest wall. Examination of abdomen did not reveal any lymphadenopathy, ascites and hepatosplenomegaly.

Biochemical and hematological investigations were within normal limits. Mass lesion in right lung was seen on chest $\mathrm{X}$-ray. Computed tomography scan it reveals solitary well defined irregular heterogeneously enhancing soft tissue density lesion measuring $10 \times 8.8 \mathrm{~cm}$ in right upper lobe suggestive of malignant neoplasm was given (Figure 1).

Computed tomography guided biopsy was done and patient was releaved symptomatically and patient was discharged. On histopathological examination of lung biopsy possibilities given as synovial sarcoma, spindle cell variant of sarcomatoid carcinoma, small cell carcinoma with predominantly spindle cell exhibition.

After one month period the patient presented with similar compliants, he underwent right posterolateral thoracotomy with right lobectomy under general anesthesia. Procedure and post-operative period uneventful.

We received right lower lobectomy specimen, on cut section well circumscribed grey white soft solid lesion(Figure 2). On histopathology showed only spindle cells arranged in fascicles, bundles with 
increased mitosis and areas of necrosis and hemorrhage(Figure 3). On immunohistochemistry tumor cells expressed epithelial membrane antigen, vimentin, $\mathrm{CD} 99, \mathrm{Bcl} 2$ (Figure 4). Hence final diagnosis given as primary synovial sarcoma of lung. Further follow up of patient symptoms subsided but complaining of loss of apetite.

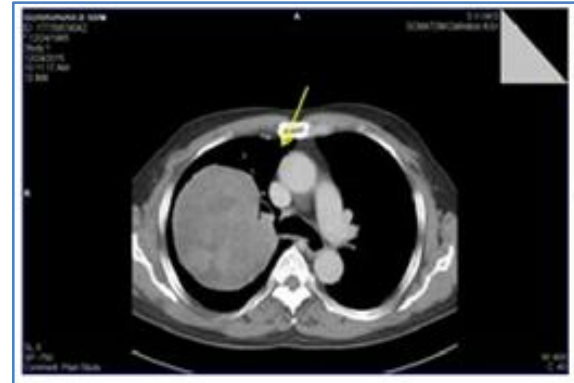

a

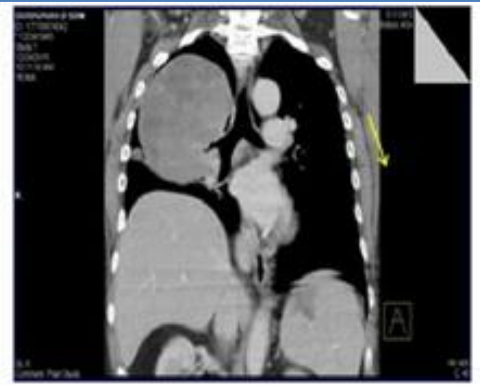

b

Axial (a) coronal (b) contrast enhanced ct images showing a large ill defined irregular heterogenously enhancing soft tissue density lesion measuring noted in right hilar region (arow in a) causing obstruction oh right upper lobe bronchus(arrow in b)

Fig-1: Axial (a) coronal (b) contrast enhanced ct images showing a large ill defined irregular heterogeneously enhancing soft tissue density lesion measuring noted in right hilar region (arrow in a) causing obstruction oh right upper lobe bronchus(arrow in b).

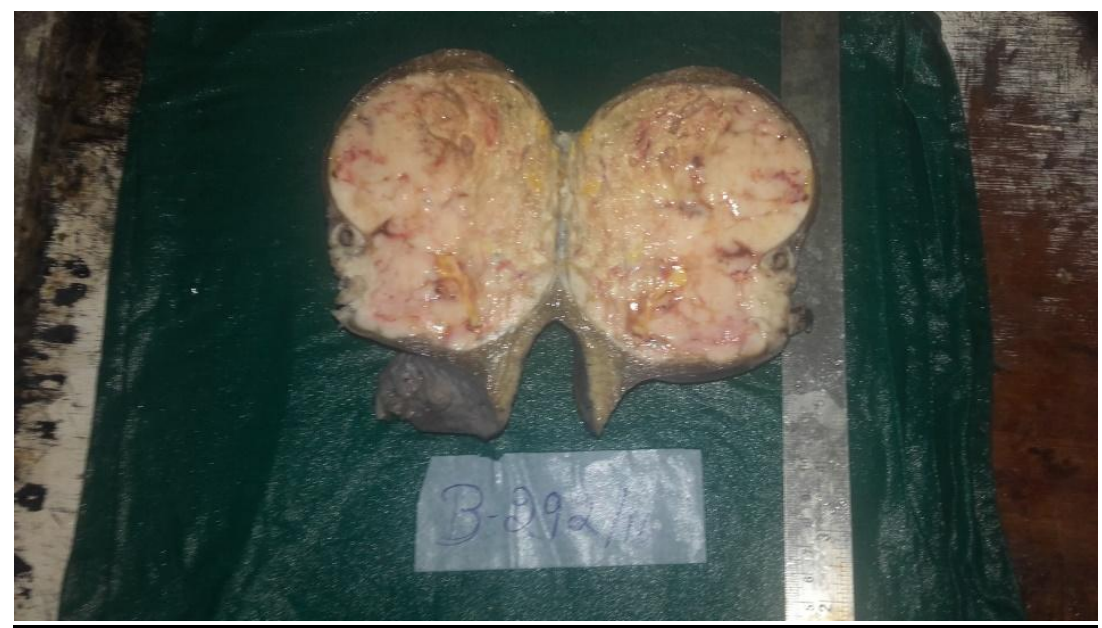

Fig-2: Right lobectomy specimen on cut section showed well circumscribed yellow to grey white solid soft lesion.

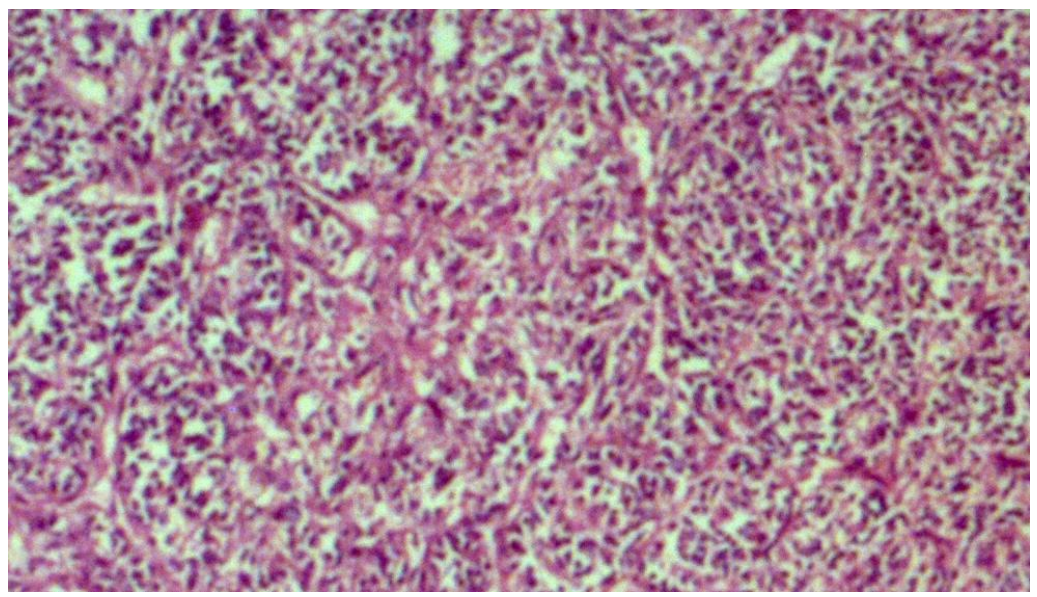

Fig-3: Microphotograph with spindle cells arranged in fascicles and bundles with increased mitosis (Hematoxylin and eosin 10X). 


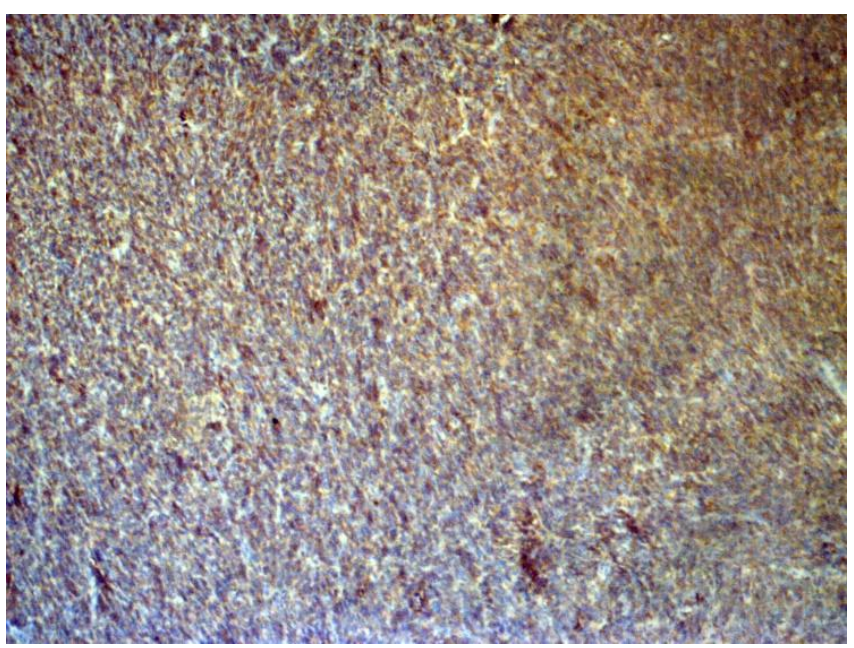

Fig-4: Microphotograph showing diffuse cytoplasmic positivity in neoplastic cells (Bcl2 10X).

\section{DISCUSSION}

Synovial sarcoma is a rare mesenchymal tumor, accounting for $10 \%$ of all soft tissue tumors. Synovial sarcoma typically presents in adolescents and young adults, most commonly in the soft tissues of the extremities but neck, lung, heart, mediastinum and abdominal wall sites have been reported [3].

SS is a highly aggressive tumor affecting males more often than females and seems to be strongly related to cigarette smoking [4].

Primary pulmonary synovial sarcomas are of four subtypes- monophasic fibrous (spindle), monophasic epithelial, biphasic and poorly differentiated [5]. Among them the monophasic neoplasm subtype occurs most often in the lung[6]. Our case showed only spindle cells arranged in fascicles and bundles with increased mitosis.

Immunohistochemistry of synovial sarcomas show immunoreactivity for cytokeratins, epithelial membrane antigen, $30 \%$ of them are S-100 positive, 60$70 \%$ CD99 and 75-100\% Bcl-2 positive[7].

The most important and common differential diagnosis is metastatic SS to the lung, which needs to be excluded with a thorough clinical and radiologic examanatinon. Otherwise the differential diagnosis is wide and includes both more common epithelial and other rare mesenchymal tumours, such as spindle cell carcinoma, malignant mesothelioma, small cell carcinoma, thymoma, fibrosarcoma, smooth muscle tumour, and malignant peripheral nerve sheath tumour and ewing sarcoma. The distinction is usually made on the basis of histologic and immunohistochemical features. In difficult cases, detection of specific cytogenetic/ molecular abnormality might be useful.

Synovial sarcoma is associated with the $\mathrm{t}(\mathrm{X} ; 18)(\mathrm{p} 11 ; \mathrm{q} 11)$, resulting in either the SYT-SSX1 or SYT-SSX2 fusion genes and subsequent transcripts.
SYT-SSX 1 gene is associated with biphasic subtype and prognosis is bad, where as monophasic subtype may have either one of two fusion transcripts, SYTSSX1 or SYT-SSX2. All tumors with SYT-SSX 2 gene show monophasic morphology[8].

Treatment of these tumors is wide surgical resection with removal of the tumor with free surgical margins with or without radiotherapy for local control [9]. The prognosis for patients with pulmonary synovial sarcoma is poor with an overall 5-year survival rate of $50 \%$. Extensive clinical examination, followed by full body CT scan to exclude primary synovial sarcoma located peripherally and distant metastases.

\section{CONCLUSION}

Primary synovial sarcoma of lung is an extremely rare and aggressive tumor. Clinical, imageological, histopathological and immunohistochemistry correlation were necessary to confirm the diagnosis and to exclude other malignant neoplasms. Long term follow up was necessary due to its aggressiveness and recurrence.

\section{REFERENCES}

1. Etienne-Mastroianni B, Falchero L,Chalabreysse L,Loire R,Ranchere D, Souquet P J. Primary sarcomas of the lung: A clinicopathologic study of 12 cases. Lung cancer.2002;38:283-9.

2. PP Roy,A Das,A Sarkar,AK Dwari and S Datta: A primary synovial sarcoma of lung. N Am J Med Sci.2012 May;4(5):241-243.

3. Mankin HJ, Hornicek FJ: Diagnosis, classification, and management of soft tissue sarcomas. Cancer Control. 2005, 12(1):5-21.

4. Weiss Sw,Goldblum JR: from malignant soft tissue tumors of uncertain type. In Enzinger and weiss's soft tissue tumors 4 th edition. Edited by: Weiss SW, Goldblum JR. St. Louis: Mosby. 2001:14831571 . 
5. Okamoto S, Hisaoka M, Daa T, Hatakeyama K, Iwamasa T, Hashimoto $\mathrm{H}$ : Primary pulmonary synovial sarcoma: a clinicopathologic immunohistochemical, and molecular study of 11 cases.Hum Pathol. 2004, 35(7):850-856.

6. Essary LR, Vargas SO, Fletcher CD: Primary pleuropulmonary synovial sarcoma: reappraisal of a recently described anatomic subset. Cancer. 2002, 94:459-469.

7. Charalampos $\mathrm{M}$ M,Antony $\mathrm{K}$,George $\mathrm{P}$,Vlassis $\mathrm{P}$ and Michel P. Primary monophasic synovial sarcoma presenting as a pulmonary mass: a case report. Journal of Medical case reports. 2008,2:18.

8. Sheri D, Eric W, George G: Primary pulmonary synovial sarcoma:A case report and review of current diagnostic and therapeutic standards.The oncologist. 2004;9:339-342.

9. Hosono T,Hironaka M, Kobayashi A, Yamasawa H, Bando M, Ohno S. Primary pulmonary synovial sarcoma confirmed by molecular detection of SYTSSX1 fusion gene transcripts: A case report and review of the literature, Jpn J Clin Oncol.2005;35:274-9. 